Alma Mater Studiorum - Università di Bologna DEPARTMENT OF ECONOMICS

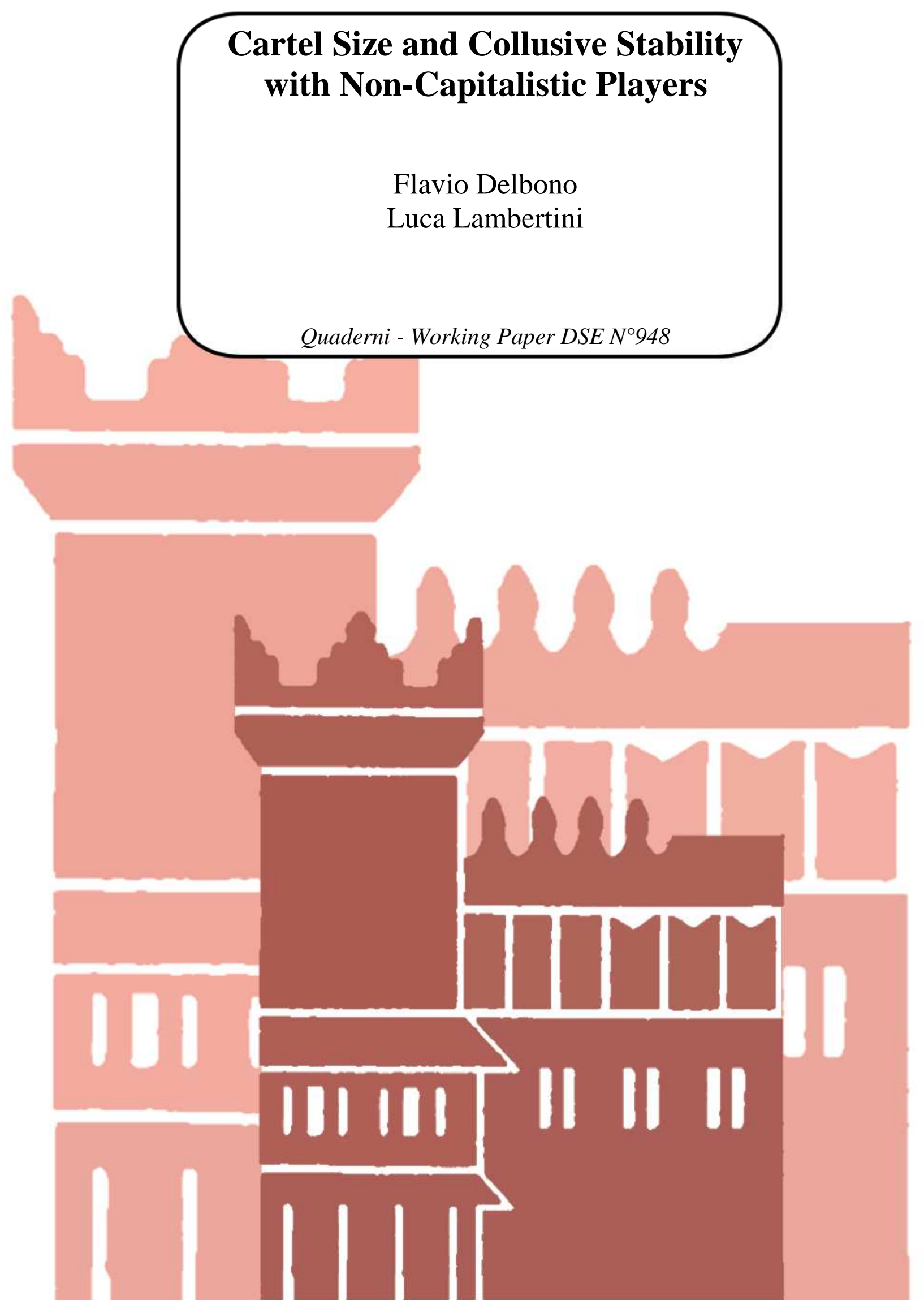




\title{
Cartel Size and Collusive Stability with Non-Capitalistic Players
}

\author{
Flavio Delbono ${ }^{\#}$ and Luca Lambertini ${ }^{\S}$ \\ Department of Economics, University of Bologna \\ \# Piazza Scaravilli 2, 40126 Bologna, Italy; flavio.delbono@unibo.it \\ $\S$ Strada Maggiore 45, 40125 Bologna, Italy; luca.lambertini@unibo.it
}

May 29, 2014

\begin{abstract}
A well established belief both in the game-theoretic IO and in policy debates is that market concentration facilitates collusion. We show that this piece of conventional wisdom relies upon the assumption of profit-seeking behaviour, for it may be reversed when firms pursue other plausible goals. To illustrate our intuition, we investigate the incentives to tacit collusion in an industry formed by Labor-Managed (LM) enterprises. We characterize the perfect equilibrium of a supergame in which LM firms play an infinitely repeated Cournot game. We show that the critical threshold of the discount factor above which collusion is stable (i) is lower in the LM industry than in the capitalistic one; (ii) monotonically decreases with the number of firms.
\end{abstract}

Keywords: cartel stability, labour-managed firms, repeated game JEL Classification: L1, L3, C7 


\section{Introduction}

It is well widely accepted from both the industrial organization literature (Tirole, 1988) and policy reports (Ivaldi et al., 2003) that high market concentration is a facilitating factor for (tacit as well as explicit) collusion. In addition to coordination being likely more difficult in larger groups, the intuition that the incentive to collusion shrinks with too many competitors is fairly simple.

"Since firms must share the collusive profit, as the number of firms increases each firm gets a lower share of the pie. This has two implications. First, the gain from deviating increases for each firm since, by undercutting the collusive price, a firm can steal market shares from all its competitors; that is, having a smaller share each firm would gain more from capturing the entire market. Second, for each firm the long-term benefit of maintaining collusion is reduced, precisely because it gets a smaller share of the collusive profit. Thus the short-run gain from deviation increases, while at the same time the long-run benefit of maintaining collusion is reduced. It is thus more difficult to prevent firms from deviating." (Ivaldi et al., 2003, p. 12)

The entire argument is put forward in terms of profits. However, many industries host also firms interested in other goals. Publicly owned firms and cooperative (sometimes labeled as Labor-Managed) firms are the most relevant instances of such non-profit seeking organizations. The question we address in this paper deals precisely with the relationship between firms' maximand and tacit collusion. Even more precisely, what happens in a repeated game when firms maximize goals other than profits? Do properties holding under profit-seeking behaviour still hold true in another plausible setting?

Among the firms that are supposed to care about goals other than profits, we shall consider the so-called Labor-Managed $(L M)$ firms, sometimes defined as cooperatives or workers' firms. Their presence is important in many countries and their performance is still under scrutiny by scholars and practitioners. ${ }^{1}$ Moreover, in many European countries we are observing a

\footnotetext{
${ }^{1}$ See Perotin (2012) for an excellent survey and a rich bibliography.
} 
resurgence of interest in cooperative firms because they seem to perform better than conventional firms in responding to the long slump (Delbono and Reggiani, 2013). Moreover, when looking at industries where $L M$ operate, one sees that they usually cohabit with profit maximizing firms (mixed oligopolies) and sometimes $L M$ are responsible for substantial fractions of the overall industrial output.

Since Ward's (1958) seminal paper, most of the theoretical literature on cooperative firms has modeled them as agents maximizing surplus per worker/member. ${ }^{2}$ If the firm does not affect the wage rate, this amounts to maximize the profit per worker. If the working time per worker is fixed, under perfect competition, Word proved that the co-op's supply function is decreasing in output price. Such celebrated result is well-known as the "perverse effect" of the cooperative firm. Moreover, this type of firms responds strangely also to increases in fixed costs; while the profit-maximizing firm shrinks output in such an event, the co-op expands its output. Similar results have been proved also under monopoly by Gal-Or et al. (1980) and Ireland and Law (1982).

Hill and Waterson (1983) are probably the first to study an oligopolistic industry formed by workers firms only. They prove that the Cournot equilibrium of such an industry is associated with a lower level of total output (and higher price) that the corresponding entrepreneurial (i.e., profit-maximizing) industry. Since then, the literature on $L M$ firms in pure or mixed oligopolies has been growing rapidly, ${ }^{3}$ but to the best of our knowledge all models assume non-cooperative behavior by all participants. ${ }^{4}$

\footnotetext{
${ }^{2}$ To be more precise, the short run objective function of such firms is taken as revenue, net of fixed costs, per worker. Sertel (1982) defines as "workers' enterprise" the case in which workers coincide with members of LM firm.

${ }^{3}$ To the best of our knowledge, the first papers modelling explicitly oligopolistic interaction between labour-managed firms and capitalistic firms are Horowitz (1991), Cremer and Cremer (1992) and Delbono and Rossini (1992).

${ }^{4}$ The only exception is Ohnishi (2012). He models a two-stage game in which LM firms choose whether to offer a donative most-favored nation policy in the first stage and then compete in prices. The kind of questions addressed in this paper makes its conclusions not comparable with ours. At any rate, Ohnishi does not investigate the relationship between
} 
The paper is organized as follows. The model is laid out in Section 2. Section 3 presents the benchmark case of implicit collusion among Cournottian profit-maximisers. Section 4 models the repeated game among $L M$ firms and establishes our core results. Section 5 concludes.

\section{The setup}

Consider a market for a homogeneous good, served by $\mathcal{N}=1,2, \ldots n$ identical firms, all endowed with the same technology. Let the market exist over discrete time $t=0,1,2, \ldots \infty$. In any period, the inverse market demand function is $p=a-Q, Q=\sum_{i=1}^{n} q_{i}$. The only variable input is labour, and firm $i$ 's output is $q_{i}=\beta l_{i}$, where $l_{i}$ is the amount of labour employed in firm $i$ and $\beta>0 .^{5}$ Hence, choosing $l_{i}$ is equivalent to choosing $q_{i}$, and the game can be thought of as being a Cournot one. Let the unit wage be $w \in(0, a)$. Additionally, each firm has to bear an exogenous fixed cost $F>0$ (say, a production license) to operate at any $t$.

In the remainder, we shall consider two alternative scenarios, in which all firms are either entrepreneurial profit-seeking units, or labour-managed enterprises. In the first case, each of them sets $l_{i}$ so as to maximise its profits

$$
\pi_{i}=(p-w) q_{i}-F=\beta\left(a-\beta l_{i}-\beta \sum_{j \neq i} l_{j}-w\right) l_{i}-F
$$

In the second case, each firm sets $l_{i}$ in order to maximise its value added per worker/member

$$
v_{i}=\frac{p q_{i}-F}{l_{i}}=\frac{\beta\left(a-\beta l_{i}-\beta \sum_{j \neq i} l_{j}\right) l_{i}-F}{l_{i}}
$$

Clearly, if $v_{i}<w$, workers do prefer to quit and offer their labour to capitalistic firms.

market concentration and collusive strategies.

${ }^{5}$ If $L_{i}$ is the number of workers (coinciding with the number of members) in firm $i$ and $\ell_{i}$ is the number of hours worked per person in the same firm, then $l_{i}=L_{i} \ell_{i}$. Therefore, any variation in $l_{i}$ might be due to a variation of either $L_{i}$ or $\ell_{i}$, or both. 
In both cases, the fully noncooperative Nash equilibria of the constituent subgame are easily characterised. Consider first the population of profit seekers. The relevant first order condition (FOC) is

$$
\frac{\partial \pi_{i}}{\partial l_{i}}=\beta\left[a-\beta\left(2 l_{i}+\sum_{j \neq i} l_{j}\right)\right]-w=0
$$

Imposing symmetry on choice variables, the above FOC simplifies as follows:

$$
\beta[a-\beta(n+1) l]-w=0
$$

which yields $l_{\pi}^{N}=(a \beta-w) /\left[(n+1) \beta^{2}\right]$, where superscript $N$ stands for Nash equilibrium, while subscript $\pi$ stands for profit-seeking. The resulting individual equilibrium profits are

$$
\pi^{N}=\frac{\left[a^{2}-(n+1)^{2} F\right] \beta^{2}-(2 a \beta-w) w}{(n+1)^{2} \beta^{2}}
$$

If instead all firms are labour-managed firms, the individual FOC is

$$
\frac{\partial v_{i}}{\partial l_{i}}=\frac{F}{l_{i}^{2}}-\beta^{2}=0
$$

so that $l_{L M}^{N}=\sqrt{F} / \beta$, with the subscript $L M$ revealing that we are looking at a labour-managed unit. ${ }^{6}$ The value added at the Nash equilibrium is $v_{L M}^{N}=[a-(n+1) \sqrt{F}] \beta$.

It is intuitively true that shrinking $l_{i}$ by all firms would increase both profits and the value added; hence, the industry might exploit the repetition of the constituent game over an infinite horizon so as to build up an implicit cartel, if firms' time preferences allow them to do so. Let $\delta \in[0,1]$ measure the discount factor, taken to be common to all firms and time-invariant. In the remainder, we will characterise the stability condition for full collusion along the monopoly frontier in both scenarios, using the perfect folk theorem (Friedman, 1971) with grim trigger strategies.

\footnotetext{
${ }^{6}$ From (4) and (6), it transpires that the second order condition for a maximum is clearly met in both cases.
} 


\section{Tacit collusion among profit-seekers}

The implicit cartel sets the vector $\mathbf{l} \equiv\left\{l_{1}, l_{2}, \ldots l_{n}\right\}$ to maximise full monopoly profits $\Pi^{M}=\sum_{i=1}^{n} \pi_{i}$, so that the relevant FOC writes as follows:

$$
\frac{\partial \Pi}{\partial l_{i}}=\frac{\partial \pi_{i}}{\partial l_{i}}+\sum_{j \neq i} \frac{\partial \pi_{j}}{\partial l_{i}}=0
$$

At the symmetric collusive equilibrium, $l_{\pi}^{C}=(a \beta-w) /\left(2 n \beta^{2}\right)$ and the individual share of cartel (monopoly) profits is

$$
\pi^{M}=\frac{\Pi^{M}}{n}=\frac{\left[a^{2}-4 n F\right] \beta^{2}-(2 a \beta-w) w}{4 n \beta^{2}}>\pi^{N}
$$

The optimal unilateral deviation from the cartel path, $l^{D}\left(l_{\pi}^{C}\right)$, solves

$$
\begin{gathered}
\frac{\partial \pi^{D}\left(l_{\pi}^{C}\right)}{\partial l^{D}\left(l_{\pi}^{C}\right)}=\beta\left[a-\beta\left(2 l^{D}+(n-1) l_{\pi}^{C}\right)\right]-w=0 \Leftrightarrow \\
l^{D}\left(l_{\pi}^{C}\right)=\frac{(n+1)(a \beta-w)}{4 n \beta^{2}}
\end{gathered}
$$

so that deviation profits are

$$
\pi^{D}\left(l_{\pi}^{C}\right)=\frac{\beta^{2}\left[a^{2}(n+1)^{2}-16 F n^{2}\right]-w(n+1)^{2}(2 a \beta-w)}{16 n^{2} \beta^{2}}
$$

In the perfect folk theorem (Friedman, 1971), the punishment triggered by any deviation from the collusive path is the infinite Nash reversion involving profits $\pi^{N}$ forever. The resulting minimum value of the discount factor above which full collusion is stable is

$$
\delta_{\pi}^{*}=\frac{\pi^{D}\left(l_{\pi}^{C}\right)-\pi^{M}}{\pi^{D}\left(l_{\pi}^{C}\right)-\pi^{N}}=\frac{(n+1)^{2}}{1+n(n+6)}
$$

It is then easily verified that $\delta_{\pi}^{*}$ in $(11)$ is concave and monotonically increasing in $n .^{7}$

\footnotetext{
${ }^{7}$ It can also be checked that $\delta_{\pi}^{*}=9 / 17$ when $n=2$, which is the standard result reported in textbook examples where duopoly is usually taken as benchmark.
} 
The foregoing analysis boils down to a well know claim, which is a synthesis of the acquired wisdom on the effect of cartel size on the stability of implicit collusion among profit-seekers:

Proposition 1 A tacit cartel made up by n profit-seeking firms becomes progressively more unstable as $n$ increases.

The intuitive explanation behind Proposition 1 is that, as $n$ grows larger, the individual share of cartel profits shrinks monotonically and therefore implicit collusion becomes harder to sustain (cf. Tirole, 1988; and Ivaldi et al. 2003, inter alia).

\section{Tacit collusion among labour-managed firms}

Now suppose the cartel is made up by $n L M$ firms. If so, the tacit cartel sets the vector $\mathbf{l} \equiv\left\{l_{1}, l_{2}, \ldots l_{n}\right\}$ to maximise $V^{M}=\sum_{i=1}^{n} v_{i}$, so that the relevant FOC writes as follows:

$$
\frac{\partial V^{M}}{\partial l_{i}}=\frac{\partial v_{i}}{\partial l_{i}}+\sum_{j \neq i} \frac{\partial v_{j}}{\partial l_{i}}=0
$$

The symmetric tacitly collusive equilibrium is $l_{L M}^{C}=\sqrt{F} /(\sqrt{n} \beta)$ and the corresponding individual firm's value added is

$$
v^{M}=(a-2 \sqrt{n F}) \beta>v^{N}
$$

The optimal unilateral deviation from the cartel path, $l^{D}\left(l_{L M}^{C}\right)$, solves

$$
\frac{\partial v^{D}\left(l_{L M}^{C}\right)}{\partial l^{D}\left(l_{L M}^{C}\right)}=0 \Leftrightarrow l^{D}\left(l_{L M}^{C}\right)=\frac{\sqrt{F}}{\beta}=l_{L M}^{N}
$$

since $L M$ firms' reaction functions are orthogonal to each other. The unilateral deviation payoff is

$$
v^{D}\left(l_{L M}^{C}\right)=\frac{[a \sqrt{n}-(\sqrt{n}(2+\sqrt{n})-1) \sqrt{F}] \beta}{\sqrt{n}}
$$


which is higher than $v^{M}$ appearing in (13). Under the grim trigger strategies of the perfect folk theorem (Friedman, 1971), the critical threshold for cartel stability is

$$
\delta_{L M}^{*}=\frac{v^{D}\left(l_{L M}^{C}\right)-v^{M}}{v^{D}\left(l_{L M}^{C}\right)-v^{N}}=\frac{1}{1+\sqrt{n}}
$$

which is evidently convex and monotonically decreasing in $n$. Hence, the analysis of the supergame among $L M$ firms reveals the following:

Proposition 2 An increase in cartel size makes implicit collusion among labour-managed firms easier to sustain.

Proof. It suffices to observe that the derivative of $\delta_{L M}^{*}=1 /(1+\sqrt{n})$ w.r.t. $n$ is negative everywhere.

The interpretation of Proposition may benefit from some algebra. To evaluate the effect of a change in $n$ on the sustainability of implicit collusion among $L M$ firms, let us rewrite the above critical threshold of the discount factor as

$$
\delta_{L M}^{*}(n)=\frac{v^{D}\left(l_{L M}^{C}, n\right)-v^{M}(n)}{v^{D}\left(l_{L M}^{C}, n\right)-v^{N}(n)}
$$

Treating $n$ as a continuous variable, we have that

$$
\begin{gathered}
\operatorname{sign}\left\{\frac{\partial\left(\delta_{L M}^{*}(n)\right)}{\partial n}\right\}= \\
\operatorname{sign}\left\{\left[\frac{\partial v^{D}(\cdot)}{\partial n}-\frac{\partial v^{M}(\cdot)}{\partial n}\right]\left[v^{D}(\cdot)-v^{N}(\cdot)\right]\right. \\
\left.-\left[\frac{\partial v^{D}(\cdot)}{\partial n}-\frac{\partial v^{N}(\cdot)}{\partial n}\right]\left[v^{D}(\cdot)-v^{M}(\cdot)\right]\right\}
\end{gathered}
$$

We already know that $v^{D}(\cdot)>v^{M}(\cdot)>v^{N}(\cdot)$. We must establish the sign of

$$
\frac{\partial v^{D}(\cdot)}{\partial n}-\frac{\partial v^{M}(\cdot)}{\partial n}
$$

and

$$
\frac{\partial v^{D}(\cdot)}{\partial n}-\frac{\partial v^{N}(\cdot)}{\partial n}
$$


Concerning (19), we have

$$
\frac{\partial v^{D}(\cdot)}{\partial n}-\frac{\partial v^{M}(\cdot)}{\partial n}=\frac{\beta(n-1) \sqrt{F}}{2 n \sqrt{n}}>0
$$

As for (20), we have

$$
\frac{\partial v^{D}(\cdot)}{\partial n}-\frac{\partial v^{N}(\cdot)}{\partial n}=\frac{\beta(2 n \sqrt{n}-n-1) \sqrt{F}}{2 n \sqrt{n}}>0
$$

Therefore, $\partial \delta_{L M}^{*} / \partial n<0$ as a result of

$$
\frac{\partial v^{D}(\cdot) / \partial n-\partial v^{N}(\cdot) / \partial n}{v^{D}(\cdot)-v^{N}(\cdot)}>\frac{\partial v^{D}(\cdot) / \partial n-\partial v^{M}(\cdot) / \partial n}{v^{D}(\cdot)-v^{M}(\cdot)}
$$

Inequality (23) compares the rates at which the numerator and denominator of $\delta_{L M}^{*}$ change as $n$ varies. What (23) says is that the denominator of $\delta_{L M}^{*}$ increases in $n$ more rapidly than its numerator; hence, $\delta_{L M}^{*}$ declines as $n$ grows. With $L M$ firms we then obtain a reversal of the standard conclusion holding under profit-maximising behaviour which is summarised by $\partial \delta_{\pi}^{*} / \partial n>0$ since, from (11), we have:

$$
\frac{\partial \pi^{D}(\cdot) / \partial n-\partial \pi^{N}(\cdot) / \partial n}{\pi^{D}(\cdot)-\pi^{N}(\cdot)}<\frac{\partial \pi^{D}(\cdot) / \partial n-\partial \pi^{M}(\cdot) / \partial n}{\pi^{D}(\cdot)-\pi^{M}(\cdot)}
$$

Then, we may claim

Proposition 3 If the intensity of the punishment increases in n more (resp., less) rapidly than the incentive to deviate from the cartel, then the critical threshold of the discount factor decreases (resp., increases) monotonically in the number of cartel members.

It is worth investigating the curvature and the limit properties of both $\delta_{L M}^{*}$ and $\delta_{\pi}^{*}$. Simple algebra shows that

$$
\begin{aligned}
& \frac{\partial^{2} \delta_{L M}^{*}}{\partial n^{2}}=\frac{3 \sqrt{n}+1}{4 n(\sqrt{n}+1)^{3} \sqrt{n}}>0 \\
& \frac{\partial^{2} \delta_{\pi}^{*}}{\partial n^{2}}=-\frac{8\left[n^{3}-3(n+2)\right]}{[n(n+6)+1]^{3}}<0
\end{aligned}
$$


for all $n>2$. Moreover,

$$
\begin{gathered}
\lim _{n \rightarrow \infty} \delta_{L M}^{*}=0 \\
\lim _{n \rightarrow \infty} \delta_{\pi}^{*}=1
\end{gathered}
$$

In words, the critical threshold for $L M$ firms is decreasing and convex in $n$ and tends to zero as $n$ becomes arbitrarily large. On the other hand, the critical threshold for profit-seeking firms is increasing and concave in $n$ and tends to one as $n$ becomes arbitrarily large. To complete the description of the behaviour of the critical thresholds w.r.t. $n$, we may also observe that

$$
\left.\delta_{L M}^{*}\right|_{n=2}=\frac{1}{1+\sqrt{2}}<\frac{9}{17}=\left.\delta_{\pi}^{*}\right|_{n=2}
$$

Figure 1 below illustrates the above properties of the critical levels of the discount factors.

Figure 1: Tacit collusion in the space $(n, \delta)$.

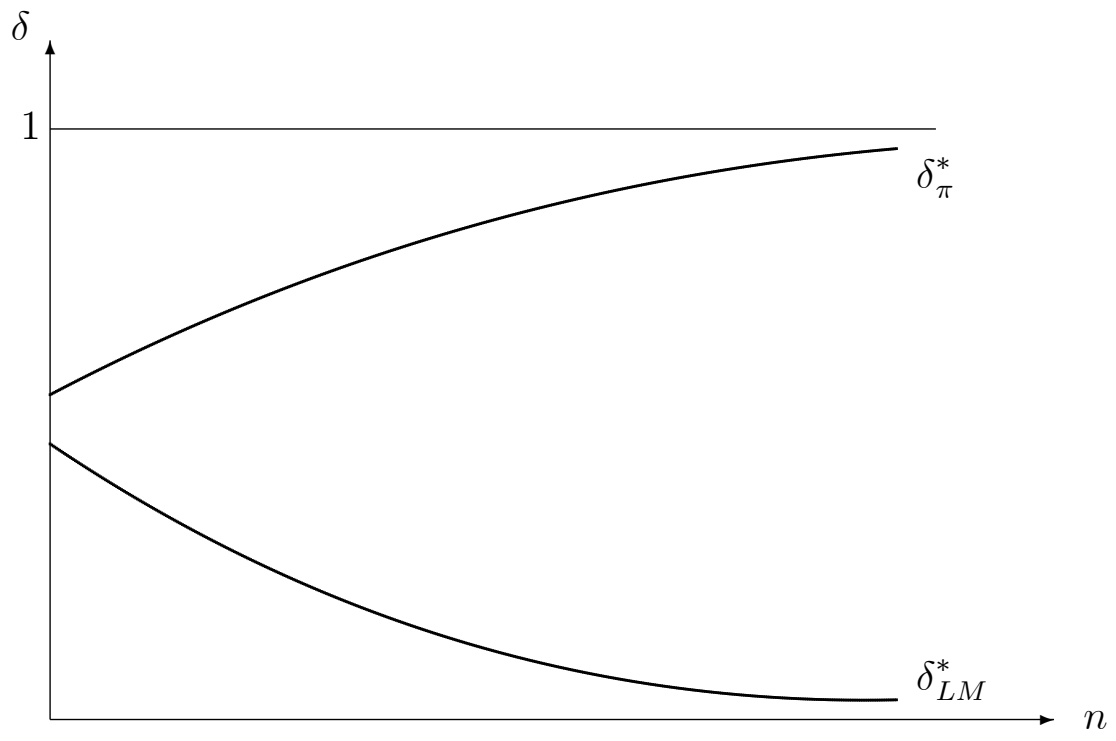

$(2,0)$

The properties we have just highlighted take us to our final result, according to which tacit collusion is more likely to be expected in an $L M$ industry than in a capitalistic one. 
Proposition $4 \delta_{\pi}^{*}>\delta_{L M}^{*}$ for all $n \geq 2$.

The intuition behind Proposition 4 relies upon the difference in firms' objective functions. To be more precise, while profit seekers aim at maximising total profits, $L M$ firms maximise profit per worker/member. Therefore, as $n$ grows, the incentive to collude intensifies for $L M$ firms while the opposite occurs for profit-seeking units.

\section{Concluding remarks}

In this paper, we have shown that the relationship between cartel stability and cartel size depends upon firms' goals. While under profit-maximising behaviour expanding cartel size diminishes cartel stability, the opposite applies if firms maximise individual value added. Therefore, under the same conditions concerning demand and technology, we should expect tacit collusion occurring more likely in an $L M$ industry than in a capitalistic one.

We believe that our model might fruitfully be extended in a few directions which we are currently exploring. The first one amounts to considering price instead of quantity as firms' choice variable in a differentiated oligopoly. The second consists in replacing the perpetual Nash reversion with one-shot stick and carrot optimal punishments à la Abreu (1986). The third amounts to considering an industry in which profit-seeking and $L M$ firms cohabit, and scrutinising the emergence of tacit collusion in such a mixed oligopoly. 


\section{References}

[1] Abreu, D.J. (1986), "Extremal Equilibria of Oligopolistic Supergames", Journal of Economic Theory, 39, 191-225.

[2] Cremer, H. and J. Cremer (1992), "Duopoly with Employee-Controlled and Profit-Maximizing Firms", Journal of Comparative Economics, 16, $241-58$.

[3] Delbono, F. and C. Reggiani (2013), "Cooperative firms and the crisis: evidence from some Italian mixed oligopolies", Annals of Public and Cooperative Economics, 84, 383-97.

[4] Delbono, F. and G. Rossini (1992), "Competition Policy vs Horizontal Merger with Public, Entrepreneurial and Cooperative Firms", Journal of Comparative Economics, 16, 226-40.

[5] Friedman, J.W. (1971), "A Non-Cooperative Equilibrium for Supergames", Review of Economic Studies, 28, 1-12.

[6] Gal-Or, E., M. Landsberger and A. Subotnik, A. (1980), "Allocative and Distributional Effects of a Monopolistic Cooperative Firm in a Capitalist Economy", Journal of Comparative Economics, 4, 158-72.

[7] Hill, M. and M. Waterson (1983), "Labor-Managed Cournot Oligopoly and Industry Output", Journal of Comparative Economics, 7, 43-51.

[8] Horowitz, I. (1991), "On the Effects of Cournot Rivalry between Entrepreneurial and Cooperative Firms", Journal of Comparative Economics, 15, 115-21.

[9] Ivaldi, M., B. Jullien, P. Rey, P. Seabright and J. Tirole (2003), "The Economics of Tacit Collusion", Final Report for DG Competition, European Commission, Brussels.

[10] Ohnishi, K. (2012), "Tacit Collusion in a Labor-Managed Oligopoly Market", Journal of Economics and Business, 14, 97-107. 
[11] Perotin, V. (2012), "The Performance of Workers Cooperatives", in Battilani, P. and H. Schroter (eds), The Cooperative Business Movement, 1950 to the Present, Cambridge, Cambridge University Press.

[12] Sertel, M. (1982), Workers and Incentives, Amsterdam, North Holland.

[13] Tirole, J. (1988), The Theory of Industrial Orgianization, Cambridge, MA, MIT Press.

[14] Ward, B. (1958), "The Firm in Illyria: Market Syndicalism", American Economic Review, 48, 566-89. 


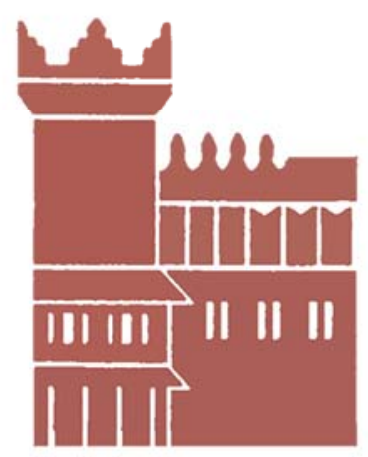

Alma Mater Studiorum - Università di Bologna DEPARTMENT OF ECONOMICS

Strada Maggiore 45

40125 Bologna - Italy

Tel. +39051 2092604

Fax +390512092664

http://www.dse.unibo.it 